\title{
Seminal plasma aids the survival and cervical transit of epididymal ram spermatozoa
}

\author{
J P Rickard ${ }^{1}$, T Pini ${ }^{1}$, C Soleilhavoup ${ }^{2}$, J Cognie ${ }^{2}$, R Bathgate $^{1}$, G W Lynch ${ }^{1,3}$, G Evans ${ }^{1}$, \\ W M C Maxwell ${ }^{1}$, X Druart $^{2}$ and S P de Graaf ${ }^{1}$ \\ ${ }^{1}$ Faculty of Veterinary Science, The University of Sydney, RMC Gunn Building (B19) Regimental Drive, Sydney, \\ New South Wales 2006, Australia, ${ }^{2}$ UMR 85 INRA, CNRS-Université de Tours-Haras Nationaux, Station de \\ Physiologie de la Reproduction et des Comportements, Institut National de la Recherche Agronomique, \\ F-37380 Nouzilly, France and ${ }^{3}$ Faculty of Medicine, The University of Sydney, Sydney, Australia
}

Correspondence should be addressed to J P Rickard; Email: jessica.rickard@sydney.edu.au

Reproduction (2014) $148 \times 1$

The authors apologise for errors in Figure 4 in the above paper published in the journal Reproduction 2014 vol 148 iss 5, pages 469-478. The superscripts in the figure had been inadvertently deleted. The correct Figure 4 along with the legend is published in full below.

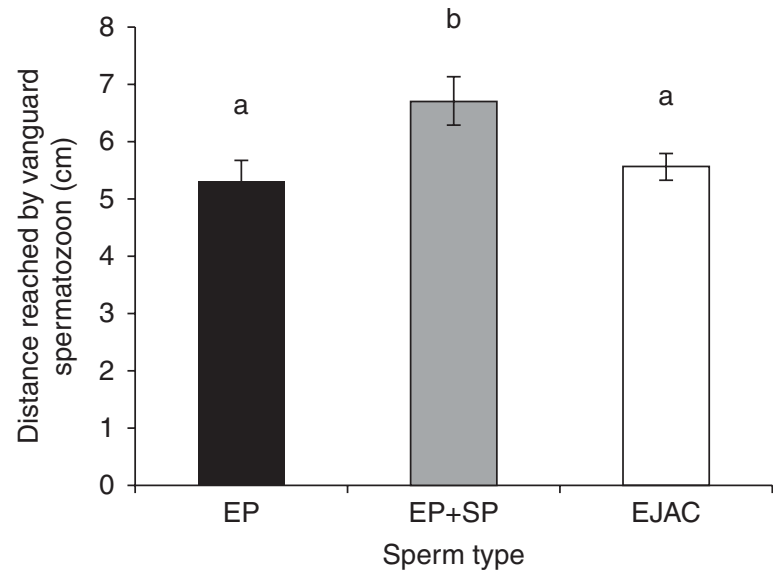

Figure 4 Distance reached by the vanguard spermatozoon of epididymal spermatozoa (EP; black column), epididymal spermatozoa exposed to seminal plasma (EP+SP; grey column) and ejaculated spermatozoa (EJAC; white column). Data are pooled over 0, 3 and $6 \mathrm{~h} \pm$ s.E.M. Columns without common superscripts differ significantly $(P<0.05)$. 